\title{
THE CROSS-BORDER HEALTH CARE DIRECTIVE: MORE FREE MOVEMENT FOR CITIZENS AND MORE COHERENT EU LAW?
}

\author{
Frans Pennings*
}

\begin{abstract}
In 2011 the Patients' Rights in Cross-border Health Care Directive was adopted. This Directive is meant, inter alia, to implement the case law of the Court of Justice on patient mobility. This article investigates the ways in which the position of patients has been reinforced. The question of whether the dual system of reimbursement of costs - on the basis of Regulation 883/2004 and on the basis of the Treaty - has been simplified, or whether it has become even more complicated, is also investigated. ${ }^{1}$
\end{abstract}

Keywords: coherence; coordination law; European citizens; European Union; health care

\section{INTRODUCTION}

On 9 March 2011, Directive 2011/24 of the European Parliament and of the Council on the application of Patients' Rights in Cross-border Health Care (henceforth, Crossborder Health Care Directive) was adopted. ${ }^{2}$ The objective of the Directive is, inter alia, to provide greater legal certainty as regards the reimbursement of health care costs (recitals 9 and 27). This became necessary after the case law of the Court of Justice, ${ }^{3}$ which interpreted Treaty provisions as requiring such reimbursement in

Frans Pennings is Professor of Labour Law and Social Security Law at Utrecht University, Professor of International Social Security Law, Tilburg University, the Netherlands, and Visiting Professor at Gothenburg University, Sweden. He is also one of the founding editors of EJSS. Address: Achter St. Pieter 200, NL 3512 HT Utrecht; tel: +31 30253 7258; e-mail: f.pennings@uu.nl.

1 EJSS wishes to make it clear that all articles are subject to an anonymous peer reviewing procedure. This applies to articles by the editors in the same way as to any other article.

2 Directive 2011/24, OJ 2011 L 88/45.

3 Case C-158/96, Kohll [1998] ECR I-1931 and Case C-120/95, Decker [1998] ECR I- I-1871. Other cases are: Case C-368/98, Vanbraekel [2001] ECR I-5363; Case C-157/99, Smits and Peerbooms [2001] 
cases where the Coordination Regulation on social security (see Section 2 below) did not.

The history of the proposal began before it was published, since a proposal on cross-border health care services was included in the draft Services Directive. ${ }^{4}$ As a result of the debate on this proposal, health care services were removed from the draft Directive, and a separate instrument was announced. Given the special nature of health care, it was regarded as inappropriate to treat this area in the same way as other services. Article 2(2)(f) of the Services Directive now provides that the Directive does not apply to health care services, whether or not they are provided through health care facilities, and regardless of the ways in which they are organised and financed at national level, or whether they are public or private. ${ }^{5}$

The Cross-Border Health Care Directive was adopted after long and difficult discussions, during which the Council and Parliament made many amendments to the draft. ${ }^{6}$

In this article I shall investigate whether and how the Directive will reinforce the legal position of patients who wish to obtain medical care abroad. Related to this question is the relationship between the Directive and the reimbursement rules of the Coordination Regulation. The case law of the Court (see note 4) led to a dual system of reimbursement of cross-border health care. Has the new Directive changed this situation, or has the system become even more complicated? Has the introduction of the new Directive led to new inconsistencies, and if so, how can these be assessed?

I shall first describe the provisions of the Coordination Regulation in relation to health care, in particular the prior authorisation requirement (Section 2) and the case law of the Court on the basis of Article 49 EC, now Article 56 TFEU, which was an important reason for making the new Directive. Since there is already an abundance of material on these topics, these sections will merely sketch the main points. ${ }^{7}$ Section 4 deals with the Directive's rules on cross-border health care. In Section 5, some conclusions will be drawn.

Not all the aspects of the Cross-Border Health Care Directive will be discussed; the centres of excellence, for instance, fall outside the scope of this article, which concerns the relationship between the Coordination Regulation, the case law on Article 56 TFEU, and the Directive.

ECR I-5473; Case C-56/01, Inizan [2003] ECR I-12403; Case C-8/02, Leichtle [2004] ECR I-2641; Case C-385/99, Müller-Fauré and Van Riet [2003] ECR I-4503; Case C-372/04, Watts [2006] ECR I-4325; Case C-444/05, Stamatelaki [2007] ECR I-3185.

4 Directive 2006/123/EC of 12 December 2006 on services in the internal market, OJ 2006 L 376.

5 See also, on this history, Baeten and Palm (2011).

6 The proposal of the Directive of the Commission was published in COM(2008) 414 final, 2 July 2008.

7 See, on the coordination rules in more detail, Pennings (2010), and, on the cross-border health care case law, Van de Gronden et al. (2011). 


\section{THE COORDINATION REGULATION AND MEDICAL CARE}

\subsection{INTRODUCTION}

On 1 May 2010, Regulation 1408/71 was replaced by Regulation $883 / 2004,{ }^{8}$ to which a double issue of this journal was dedicated. ${ }^{9}$ The provisions of the Regulations relevant to our main topic (sickness benefits in kind in the case of planned health care) remained, however, essentially the same.

An important difference between the two Regulations was that Regulation 1408/71 was basically limited to employed and self-employed persons, whereas the new Regulation covers all EU nationals who have been covered by a social security scheme, as well the members of their families and their survivors. Third country nationals are, however, not completely excluded from the application of the Coordination Regulation: Regulation 1231/2010 extends the provisions of the Coordination Regulation to nationals of third countries who are not already covered by these provisions, solely on the ground of their nationality, as well as to members of their families and to their survivors, provided they are legally resident in the territory of a Member State. An important condition is that they are in a situation that is not confined, in all respects, within a single Member State. ${ }^{10}$

The material scope of Regulation 883/2004 includes all sickness benefits in kind regulated by statutory law. Purely private schemes are, thus, excluded, but if the contents of a private scheme are regulated by statutory law, it is also covered.

In view of the comparison with the Directive on cross-border health care, I shall focus on the rules on medical care that are needed abroad by persons who stay in a state other than the state of affiliation. I shall therefore not discuss the situation of persons who reside ('live') ${ }^{11}$ in a state other than the competent one, for instance, frontier workers or pensioners. ${ }^{12}$

8 Regulation (EC) No 883/2004 of the European Parliament and of the Council of 29 April 2004 on the co-ordination of social security systems (OJ 2004, L 166).

9 The double issue was Issue 11(1-2) (2009). In it, Marhold (2009) discusses the rules of the new Regulation on medical care.

10 Regulation 1231/2010, OJ 2010, L 344.

11 Article 1(j) of Regulation 883/2004 defines 'residence' as 'habitual residence' This term refers to the state in which the person concerned habitually resides, and where the habitual centre of their interests is to be found. In that context, the Court ruled, account should be taken, in particular, of the employed person's family situation, the reasons which have led him to move, the length and continuity of his residence, the fact (where this is the case) that he is in stable employment, and his intention, as it appears from all the circumstances.

12 See, on the rules relevant to them, Pennings (2010). 


\subsection{MEDICAL CARE WHICH BECOMES NECESSARY DURING A STAY ABROAD}

The first rule to be mentioned concerns the situation of a person whose condition requires benefits in kind which become necessary, on medical grounds, during a stay in the territory of another Member State (Article 19 of Regulation 883/2004). This provision is important, for instance, if you break your leg or suffer a heart attack when you are abroad. If, however, you are already ill and ask for treatment in a Member State different from the one in which you are insured, this article is not applicable (Section 2.3, below, concerns this situation).

If Article 19 is applicable, the patient is entitled to benefits in kind from the institution of the place of stay, e.g. the local doctor, hospital and ambulance. No authorisation by the competent institution of the competent state is necessary. ${ }^{13}$ The institution of the place of stay has to apply the provisions of the legislation that it administers as though the patient was insured with it. So, the contents of the care (including cost sharing, if any, by the patient) are defined by the legislation of the state of stay. The costs of the institution of the state of stay are paid for by the state of affiliation.

From this provision, it follows that if, for instance, the patient has to pay part of the costs in the state of stay him/herself, the state of affiliation need not reimburse these costs, even where it does not require cost sharing in its own health care system. This differs from planned care (see below). In Commission v. Spain the Court ruled that this effect is not contrary to (what is now) Article 56 TFEU (Section 3.5). ${ }^{14}$

In general, the application of this provision is not problematic, although there were some discussions on the interpretation of the phrase 'when medical care becomes necessary'. ${ }^{15}$ Another implementation problem is that care providers do not always know or apply the rules.

\subsection{GOING ABROAD TO OBTAIN PLANNED CARE}

Article 20 of the Regulation concerns a more controversial situation, i.e. that of persons who go to another state with the objective of obtaining health care in that state. Article 20(2) provides that an insured person may be authorised by the competent institution to go to the territory of another Member State to receive the appropriate treatment for his/her condition.

If $s /$ he obtains this authorisation, $s /$ he is entitled to benefits in kind provided on behalf of the competent state by the institution of the place of stay (Member State

\footnotetext{
13 See, for the interpretation of who has to decide whether care has become necessary, and which treatment is to be given, Case C-145/03, Keller [2005] ECR I-2529.

14 Case C-211/08, European Commission v. Spain, not yet reported in the ECR.

15 The Administrative Commission, based on the Coordination Regulation, made some rules on this (these were published in OJ 2010, C 106).
} 
of treatment). The treatment is provided in accordance with the provisions of the legislation the place of stay administers, as though the patient were insured with it. Thus, if a hospital in another country offers a special type of operation that is appropriate for the patient, the patient can seek permission from his/her own institution to be allowed to be treated in that hospital. The term 'allowed' is only relevant, of course, to the reimbursement, and not to the treatment, but it is obvious that reimbursement is often essential to being able to undergo treatment.

When authorisation is obtained, the cost of that treatment is borne by the competent state, which refunds the institution of the Member State of treatment directly, at the rate of reimbursement normally applicable in the Member State of treatment. So, the patient does not have to advance the costs; if the costs are higher than in the competent state, these are borne by the latter.

A patient failing to obtain authorisation because the conditions of the Regulation have not been fulfilled is not eligible for reimbursement for treatment received in another Member State. However, if s/he has applied for permission, but that was wrongfully refused, a different rule applies. The Court has ruled that this person is entitled to be reimbursed directly by the competent institution with an amount equivalent to that which it would ordinarily have paid if authorisation had been granted in the first place. This was decided in the Vanbraekel judgment. ${ }^{16}$

Member States are often reluctant to grant authorisation, since they fear the higher costs ensuing from treatment abroad; by allowing people to receive treatment abroad the care capacity of the sending country increases, and thus, also, the costs. Moreover, the costs of treatment abroad may be higher than in the home country. Sometimes states fear that the quality and safety of treatment abroad are not guaranteed.

Patients ask for treatment abroad because it may be available sooner than in the Member State of residence (because of a waiting list there), the treatment may not (yet) be available in the Member State of residence, or may be available only on an experimental basis.

In the past decade, patient mobility has increased through the availability of information (e.g. on the internet) on the possibility of obtaining medical treatment in other countries, and through the activities of intermediaries, such as care brokers. ${ }^{17}$ Still, overall, only a very small proportion of all patients obtain care abroad. ${ }^{18}$

\subsubsection{Mandatory authorisation}

Whereas the provision mentioned above governs the (discretionary) powers to grant authorisation, in some situations the administration is obliged to grant authorisation.

Case C-368/98, Vanbraekel [2001] ECR I-5363.

17 Advocate General in the Watts case (opinion delivered on 15 December 2005, Case C-372/04, no. 22).

18 Estimates are that cross-border health care represents around 1 per cent of public expenditure on health care (2008 figures, European Commission, 2008: 9). 
Article 20(2) (second sentence) lays down two conditions which, if both are satisfied, render authorisation mandatory. The first condition requires the treatment in question to be among the benefits provided for by the legislation of the Member State in whose territory the insured person resides. The second condition requires that the treatment which the latter plans to undergo in a Member State other than the one in which s/he resides cannot be given within the time normally necessary for obtaining the treatment in question in the Member State of residence, taking into account his/her current state of health and the probable course of his/her disease.

Whether a treatment is part of the national system of the state of affiliation is therefore relevant. In Elchinov ${ }^{19}$ the Court provided some clarification of the meaning of this concept: Member States are free to organise their social security systems, and each Member State can, in its legislation, determine the conditions for the grant of social security benefits. Only those national bodies that have to decide on the authorisation can determine whether that treatment is included in such a list. Nevertheless, Member States are required not to disregard European Union law in the exercise of their powers. Therefore, the conditions attached to the grant of such authorisation must not exceed what is objectively necessary for that purpose, and the same result cannot be achieved by less restrictive rules. Such a system must, in addition, be based on objective, non-discriminatory criteria, which are known in advance, in such a way as to circumscribe the exercise of the national authorities' discretion, so that it is not used arbitrarily.

The Bulgarian list of medical benefits reimbursed did not expressly and precisely specify the treatment method applied, but defined types of treatment. Therefore, it was for the competent institution of the Member State of residence of the insured person to assess - applying the usual principles of interpretation and on the basis of objective and non-discriminatory criteria, and taking into consideration all the relevant medical factors and the available scientific data - whether that treatment method corresponded to benefits provided for by the legislation of that Member State. However, it also follows that if such is the case, an application for prior authorisation cannot be refused on the ground that such a treatment method is not available in the Member State of residence of the insured person. That would mean a restriction within the scope of the second subparagraph of Article 20(2).

The second condition mentioned for mandatory authorisation is that the treatment cannot be given to the insured person within the time normally necessary for obtaining that treatment in the Member State of residence, taking into account his/her current state of health and the course of the disease. In the present case, the national court had stated that the treatment in question could not be given in Bulgaria, and that the surgery available in this State, in its opinion, could not be regarded as an identical treatment, or as having the same degree of effectiveness. Although the fact that the treatment proposed in another Member State was not carried out in the Member State

19 Case C-173/09, Elchinov, not yet reported in the ECR. 
of residence of the insured person does not imply, per se, that the second condition set out in Article 20(2) was met, that must be the case where no treatment having the same degree of effectiveness can be given without undue delay.

Thus, in a situation where the treatment in question cannot be given in the Member State in whose territory the insured person resides, and the benefits provided for by the legislation of that Member State are not given as an exact list of treatments or treatment methods, but as a more general definition of categories or types of treatment or treatment methods, the second subparagraph of Article 20 implies that if it is established that the treatment proposed in another Member State falls within one of these categories or corresponds to one of these types, the competent institution is required to give the insured person the authorisation necessary for the reimbursement of the cost of that treatment, when the alternative treatment which can be given without undue delay in the Member State of his residence is not - as in the situation described by the national court - equally effective.

\section{PLANNED CARE REIMBURSED ON BASIS OF THE TREATY}

\subsection{THE KOHLL AND DECKER CASE LAW}

Two Luxembourg families bypassed the coordination rules on planned care by obtaining prescription spectacles from an ophthalmologist established in Luxembourg and orthodontist treatment for their children, respectively, without having obtained authorisation. Because of the lack of authorisation, reimbursement was refused. Questions by the national courts led to the Kohll and Decker judgments. ${ }^{20}$

In this case law, the authorisation rules of the regulation were confronted with the Treaty provisions on the freedom of goods and services: Articles 28 and 49 EC (after 1 January 2010 Articles 38 and 56 Treaty on the Functioning on the European Union, TFEU). ${ }^{21}$

As Baquero Cruz (2011) points out, the application of these articles for the benefit of individuals (clients, patients, etc.) had already been set out in the Luise and Carbone judgment: ${ }^{22}$ after this judgment it was no longer only the freedom of the service provider which was protected by the Treaty provision on services, but the freedom of recipients was also considered to be protected. Thus, recipients also have the freedom to acquire these services on the basis of the Treaty. ${ }^{23}$

\footnotetext{
20 Case C-158/96, Kohll [1998] ECR I-1931 and Case C-120/95 Decker [1998] ECR I-1871.

21 See, on the case law on cross-border health care, inter alia, Baquero Cruz (2011) and Jorens (2003).

22 Cases 286/82 and 26/83 [1984] ECR 377.

23 A crucial point in criticism of the Court's case law is that the Court often treats medical care as an economic good, and that the Court is quite short on its arguments for this. However, one can
} 
In the Kohl and Decker judgments, the Court ruled that the condition of authorisation of the Coordination Regulation was in some cases inconsistent with the mentioned Treaty provisions. The argument was as follows. The coordination article is not, according to the Court, intended to regulate, and hence, does not, in any way, prevent the reimbursement by Member States, at the tariffs in force in the competent state, of costs incurred in connection with treatment provided in another Member State, even without prior authorisation.

The question was, therefore, whether the disputed national rules were consistent with the Treaty provisions on freedom to provide services or goods. To answer this question the Court examined whether the disputed rules constituted a restriction on the freedom to provide services or goods and, if so, whether they were objectively justified. The Court held that health care is, indeed, subject to these provisions, and thus, is to be considered an economic good. It ruled that the disputed rules do not deprive persons of the possibility of approaching a provider of services established in another Member State, but the rules deter insured persons from approaching providers of medical services established in another Member State, as the costs incurred in that State are not reimbursed. Therefore, whether or not there was an objective justification was relevant. Thereupon, the Court held that the risk of seriously undermining the financial balance of the social security system could constitute an overriding reason in the general interest capable of justifying a barrier of the kind at stake. However, it is clear that reimbursement of the costs of dental treatment provided in other Member States, in accordance with the tariff of the state of insurance, has no significant effect on the financing of the social security system. Consequently, the ensuing costs for Luxembourg were not higher than if the glasses and dental treatment were bought in that state. The argument that the quality of medical care could be in danger was not accepted as an objective justification: the Court referred to several Directives concerning the mutual recognition of diplomas that would guarantee the quality of the health care. In both judgments, the reimbursement had to be given in accordance with the tariffs of the state of insurance.

As a result of this case law, there are two different systems of reimbursement: according to the Coordination Regulation, reimbursement is according to the rates of the state of treatment, and according to the case law based on Article 56 TFEU, reimbursement (to the patient) is determined according to the rates of the state of affiliation. ${ }^{24}$

The Kohll and Decker judgments led to much confusion in the Member States, as they feared their effects. Several cases were brought before the Court, in which it was discussed whether the Kohll and Decker case law also applies to hospitals and

expect that under the present Union law, the same result can also be reached using the provisions of European citizenship, since this also provides for the right to free movement.

24 The Regulation uses the term 'competent state', in the context of the Treaty, and in the Directive the term 'state of affiliation' is used. The differences between the two terms are irrelevant to the present contribution. 
to systems in which all care is provided in kind, rather than being reimbursed. The answers of the Court are discussed below.

\subsection{THE AUTHORISATION REQUIREMENT IS ALLOWED FOR HOSPITAL CARE AND MAJOR MEDICAL EQUIPMENT}

The question of whether treatment in hospitals is excluded from the application of the Treaty provisions was one of the subjects of the Geraets-Smits and Peerbooms judgment. ${ }^{25}$ In this judgment, the Court argued that in as far as medical services provided within a hospital infrastructure are concerned, an authorisation system could be objectively justified.

According to the Court, an authorisation requirement can be justified by the possible risk of seriously undermining a social security system's financial balance if this constitutes an overriding reason in the general interest capable of justifying a barrier to the principle of freedom to provide services. Likewise, the Court recognised that the objective of maintaining a balanced medical and hospital service open to all can be an objective justification. Article 46 EC (now Article 52 TFEU) allows Member States to restrict the freedom to provide medical and hospital services, in so far as the maintenance of treatment capacity or medical competence on national territory is essential for the public health, and even the survival, of the population.

The Court accepted that in comparison to medical services provided by practitioners in their surgeries or at the patient's home, medical services provided in a hospital take place within an infrastructure with a number of very distinct characteristics. This is because in determining the number of hospitals, their geographical distribution, the mode of their organisation, the equipment with which they are provided, and even the nature of the medical services which they are able to offer, a good planning system is necessary. This has to ensure that there is sufficient and permanent access to a balanced range of high-quality hospital treatment. It also assists in meeting a desire to control costs and to prevent, as far as possible, any wastage of financial, technical and human resources. If insured persons were at liberty to use the services of hospitals with which their sickness insurance fund had no contractual arrangement, all the planning which goes into the contractual system in an effort to guarantee a rationalised, stable, balanced and accessible supply of hospital services would be jeopardised at a stroke.

In the Müller-Fauré and Van Riet judgment ${ }^{26}$ the Court admitted that the distinction between non-hospital and hospital care might sometimes prove difficult to make. In particular, certain services usually provided in a hospital environment, but which can also be provided by a practitioner in his/her surgery or in a health centre, could, for that reason, be placed on the same footing as non-hospital services. Since

25 Case 157/99 [2001] ECR I-5473.

26 Case C-385/99 [2003] ECR I-4503. 
the national court and the governments did not ask questions on this issue, the Court did not consider this issue in further detail.

So, whether authorisation may be required does not automatically depend on the distinction between hospital and non-hospital care, but on the question of whether the care needs planning, without which, under-use of the care, or a disproportionate burden on the budget, can occur.

This was confirmed in the European Commission v. France judgment, ${ }^{27}$ in which the Court clarified that the authorisation requirement is allowed not only for hospital services, but also for major medical equipment used outside the hospital setting. For such equipment planning may also be necessary, and thus, may constitute a reason for allowing an authorisation requirement.

More specifically, the case concerned major medical equipment, exhaustively listed in a provision of the French Public Health Code, which was the subject of planning policy, such as that defined by the national legislation at issue, with particular regard to quantity and geographical distribution, in order to help ensure, throughout national territory, a rationalised, stable, balanced and accessible supply of up-to-date treatment, and also to avoid, as far as possible, any waste of financial, technical and human resources. Such waste would be all the more damaging because the conditions for the installation, operation and use of the five types of equipment exhaustively listed in the Public Health Code were especially onerous, while the budgetary resources which the Member States were able to make available for up-to-date treatment and, in particular, the subsidising of such equipment, was not unlimited, whatever the mode of funding applied. Therefore, if persons insured under the French system could, freely and in any circumstances, obtain, at the expense of the competent institution, from service providers established in other Member States, treatment involving the use of major medical equipment corresponding to that listed exhaustively in the Public Health Code, the planning endeavours of the national authorities and the financial balance of the supply of up-to-date treatment would, as a result, be jeopardised.

\subsection{EXCLUSION OF NON-REIMBURSEMENT SYSTEMS?}

In the Watts judgment, ${ }^{28}$ the Court was asked again whether medical care was subject to the free movement provisions, this time, since it was provided under the British National Health Service (NHS). Although the organisation of the NHS is different from other systems (it is paid from taxes rather than from contributions, and service providers are public bodies rather than private entities), the Court could only decide that the Treaty rules are also relevant to this system. It referred to its consistent case law that since medical services are being paid for, they constitute an economic activity,

\footnotetext{
27 Case C-512/08, European Commission v. French Republic, not yet reported in ECR.

28 Case 372/04 [2006] ECR I-4325.
} 
whatever the form of payment and whoever pays for it. ${ }^{29}$ Although Member States kept challenging this approach, a different interpretation by the Court could not really be expected: 'Once the door of economic activity has been opened, it is difficult to close it for just one kind of system', as Baquero Cruz remarks. ${ }^{30}$ In Section 6.1, I shall make a more general assessment of the case law.

\subsection{CRITERIA FOR REFUSING AUTHORISATION}

In the Watts judgment the Court also discussed the criteria for refusing authorisation. It considered that a starting point for establishing the criteria is that Member States must not disregard European Union law. A prior administrative authorisation scheme must be based on a procedural system that is easily accessible and capable of ensuring that a request for authorisation will be dealt with objectively and impartially within a reasonable time. Refusals to grant authorisation must be capable of being challenged in judicial or quasi-judicial proceedings. They must refer to the specific provisions on which they are based, and they must be properly reasoned in accordance with them.

Authorisation may be refused only if the same, or an equally effective, treatment can be obtained without undue delay. In the Müller-Fauré and Van Riet case (mentioned in Section 3.2), the Court was asked to interpret the meaning of this term. It replied that a refusal to grant prior authorisation that is based not on fear of wastage resulting from hospital overcapacity, but solely on the ground that there are waiting lists, is an unjustified restriction. Instead, it is essential that the specific circumstances attaching to the patient's medical condition are also taken into account. The national authorities are required to consider all the circumstances of each specific case. They have to take due account of the patient's medical condition at the time when authorisation is sought. They also have to take account, where appropriate, of the degree of pain, or of the nature of the patient's disability, which might, for example, make it impossible, or extremely difficult, for him to carry out a professional activity. Finally, they have to take account of his medical history.

\subsection{THE RELATIONSHIP BETWEEN ARTICLE 22 OF THE REGULATION AND ARTICLE 56 TFEU}

From the foregoing, it follows that the applicability of Article 20 of the Regulation does not mean that Article 56 TFEU cannot apply at the same time. The Regulation, therefore, has to be interpreted in line with this Treaty provision. This is relevant, for instance, in deciding the extent to which the state of affiliation has to reimburse the costs of planned care.

\footnotetext{
29 See, for instance, Case C-157/99, Smits and Peerbooms [2001] ECR I-5473, cons. 53-57.

30 Baquero Cruz (2011: 81).
} 
In the Watts judgment the Court held that if an insured person who has been authorised to receive care in another Member State, in accordance with the Regulation, is not given a level of insurance cover equivalent to that in the Member State of affiliation, this constitutes a restriction of the freedom to provide services. This is the case, since it may deter, or even prevent, that person from applying to service providers established in other Member States.

In this respect, there is a difference in respect of unplanned care (mentioned in Section 2.2). In Commission v. Spain, ${ }^{31}$ the Court ruled that in the case of unplanned treatment, the circumstances - e.g. the urgency of the situation, the seriousness of the illness or the accident, or the fact that a return to the Member State of affiliation has been ruled out for medical reasons - leave no alternative but to provide the insured person with hospital treatment in an establishment in the Member State of stay. Therefore, the Court argued, following a strict economic logic, the legislation at issue could not be regarded as having any restrictive effect on the freedom of service providers established in another Member State to provide services. Thus, this provision does not have to be interpreted in the light of Article 56 TFEU.

\subsection{SUMMARY}

If a person is authorised to receive the treatment appropriate for his condition abroad, the Member State where s/he is covered refunds the costs to the institution of the Member State of treatment directly, in accordance with the Regulation. Thus, the full costs of the institution are paid, as they apply in the state of treatment. ${ }^{32}$ In the case of non-hospital care or if no major equipment is used, benefits can also be obtained without authorisation on the basis of Article 56 TFEU; in these cases reimbursement is determined with the reimbursement scales of the state of affiliation. The amount may be different from the costs incurred in the state of treatment.

In the case of hospital care and some major equipment, the possible risk of seriously undermining a social security system's financial balance may constitute an overriding reason in the general interest capable of justifying a barrier to the principle of freedom to provide services, and thus, may allow a system of prior authorisation. This system must be in line with European Union law and must be based on a procedural system that is easily accessible and capable of ensuring that a request for authorisation will be dealt with objectively and impartially within a reasonable time, and refusals to grant authorisation must also be capable of being challenged in judicial or quasi-judicial proceedings.

In the case of a request in view of a delay resulting from a waiting list, the national authorities are required to consider all the circumstances of each specific case, and to take due account, not only of the patient's medical condition at the time when

\footnotetext{
$31 \quad$ Case C-211/08, European Commission v. Spain, not yet reported in the ECR.

32 This does not mean that all costs of the patient are reimbursed.
} 
authorisation is sought, and, where appropriate, of the degree of pain or the nature of the patient's disability, which might, for example, make it impossible or extremely difficult for him/her to carry out a professional activity, but also of his or her medical history.

\section{THE CROSS-BORDER HEALTH CARE DIRECTIVE}

\subsection{INTRODUCTION}

If rights are based on case law only, it is difficult for patients and administering bodies to know exactly what their rights and duties are. This is all the more true in a context in which Member States have problems accepting cross-border health care without authorisation, and in which administrative and reimbursement procedures do not make obtaining health care abroad easy. Patients are also often not adequately informed of their rights.

In order to improve this situation, the Directive on cross-border health care was prepared. The Directive requires adjustment of national schemes, if necessary, in order to meet its requirements. This means that the rules established by the Court now have to be laid down in national legislation, or, more precisely, the rules required by the Directive have to be implement, which may - as we will see below - differ from the case law.

As a result, cross-border health care on the basis of the Treaty should become much more accessible to citizens, care providers, and the authorities themselves, who no longer have to deduce them solely from the case law of the Court of Justice. Thus, an important objective of the Directive is to increase legal certainty in the field of cross-border care. Of course, the Directive has to be consistent with the Treaty, and thus, also with the case law of the Court discussed above. If it is not, the risk exists that the Directive will be overruled by new case law. As we will see below, this risk indeed exists, since there are differences between the approach of the Court and the Directive.

Before continuing the discussion on the legal aspects of making an instrument to regulate the effects following from the case law, it is important to describe the political context of the topic.

Cross-border patient rights have several dimensions. The first is that of the European citizen; particularly since the EU has been losing popularity. The European Commission has been undertaking initiatives to highlight the advantages of EU law, including the increased possibilities of free movement. The case law on crossborder patient rights can be considered to fit with these advantages. In order to make these rights easier to invoke, the Directive is, therefore, an important instrument. The Cross-Border Health Care Directive is, therefore, relevant to the development of European citizenship. 
The other dimension is that of national citizens. Cross-border health care is an area where clearly there may be tensions between the interests of national and European citizens. What if the country of affiliation can no longer afford its health care system because some of its citizens go abroad to obtain (expensive) health care? What if the citizens of the country of treatment are confronted with longer waiting lists because of the influx of foreigners?

Both the citizens of the country of affiliation and the country of treatment may be worried about the new rights, and these worries explain the political complications with the proposal for the Directive. At the same time, it must be noted that the crossborder movement of patients is still very small, ${ }^{33}$ so such dangers are, and are likely to remain, hypothetical. However, in theory, the tension between the domestic situation and free movement could be considerable. In order to avoid unrest, some areas of health care were excluded from the Directive, as we shall see in Section 4.2, because it would be unacceptable for national citizens if a shortage in donor organs, care, and public vaccinations, occurred as a result of free movement. Financial problems were also feared, and the discussion of the Directive, therefore, not only aimed at the transposition of the case law but also at regulating, or even reducing, the impact of case law.

After the Commission's proposal on the Directive was published, several meetings of the Council took place, and the presidencies made several proposals for amendments to the original text in order to find a compromise. These led to considerable changes to the proposal. ${ }^{34}$ The European Parliament also proposed numerous (122) amendments to the draft Directive, many of which were adopted by the Council. ${ }^{35}$ Finally, the Directive was adopted on 9 March 2011. The Directive has to be transposed by 25 October $2013 .^{36}$

\subsection{THE MAIN ELEMENTS OF THE DIRECTIVE}

\subsubsection{The definition of health care}

Article 2 of the proposal contains a very broad definition of health care: it applies to the provision of health care regardless of how it is organised, delivered and financed or whether it is public or private.

This appeared to be a very sensitive issue, and during the discussions in the Council, the definition of health care was narrowed considerably. The Directive now defines health care in terms of health services provided by health professionals to patients, to assess, maintain or restore their state of health, including the prescription,

\footnotetext{
33 The European Commission estimated that cross-border health care represents around 1 per cent of public expenditure on health care (see note 19).

34 An important step was the Presidency proposal 15560/09 of 11 November 2009.

35 Doc. 8903/09.

36 See, on the directive, also Szyszczak (2011); Davies (2011); Sauter (2009).
} 
dispensing and provision of medicinal products and medical devices. Moreover, Article 3 defines the terms medicinal product, medical device and prescription by referring to Directives in which these terms are defined.

Parts of health care were also explicitly excluded from the scope of the Directive (Article 1(3)):

(a) services in the field of long-term care the purpose of which is to support people in need of assistance in carrying out routine, everyday tasks;

(b) allocation of, and access to, organs for the purpose of organ transplants;

(c) public vaccination programmes against infectious diseases which are exclusively aimed at protecting the health of the population on the territory of a Member State and which are subject to specific planning and implementation measures.

The definition of health care in Article 2 means that there can be differences with the Coordination Regulation. Under Regulation 883/2004, there is no definition of 'benefits in kind'. Instead, the term refers to the contents of the legislation of the competent State, and the Court has given the term a broad interpretation, e.g. in the Molenaar judgment. ${ }^{37}$ In this judgment, (long-term) care was also interpreted as falling under benefits in kind. In the Directive, such care is explicitly excluded.

The care referred to in the exceptions has not yet been dealt with in the case law of the Court on Article 56 TFEU. Since it is an economic activity in the same sense as other sickness benefits in kind, it is likely that it falls within the scope of this article. The only reason it is not covered by the Directive is because of the fear of large costs for the state of affiliation. Exclusion from the scope of the Patients' Directive therefore does not mean that it cannot be covered by the Treaty provisions on free movement.

Restrictions to free movement could be based on the type of objective reasons discussed in the previous section: the need for planning and the fear of a financial imbalance. It is not yet clear whether such reasons exist for long-term care. Whether this will be the case will probably depend on the type of long-term care provided. If long-term care needs long-term investment, restrictions are more likely to be acceptable than if it concerns individual help for persons in their homes. In any case, excluding this part completely from the Directive leaves legal uncertainty intact because of the impact of the free movement provisions.

For the other two excluded areas (organs and vaccination programmes), it may be assumed that the public order and general health exceptions to the free movement of services of the Treaty allow for these exclusions, and that the new text does not cause problems.

37 Case 160/96, Molenaar [1998] ECR I-880. 


\subsubsection{The rules on authorisation}

4.2.2.1. The three categories of care for which a prior authorisation requirement is allowed

The Directive itself does not introduce a general prior authorisation system; its objective is merely to regulate such systems of Member States.

The European Commission's proposal strictly followed the distinction made by the Court between hospital and non-hospital care as a criterion for determining whether or not authorisation was required. Hospital care and non-hospital care were therefore dealt with in separate articles.

This approach is no longer followed after amendments to the text: the heading of Article 8 now reads: 'Health care that may be subject to prior authorisation'. As the reader will expect, this means that prior authorisation can be requested in a broader set of situations than for hospital care alone.

The Article holds - as a general condition for a system of prior authorisation that the system, including the criteria and individual decisions, has to be restricted to what is necessary and proportionate to the objective to be achieved, and may not constitute a means of arbitrary discrimination or an unjustified obstacle to the free movement of patients. Member States have to make all relevant information on the prior authorisation systems publicly available.

For the following categories prior authorisation may be requested: Category (a-i) concerns 'health care which is made subject to planning requirements relating to the objective of ensuring sufficient and permanent access to a balanced range of highquality treatment in the Member State concerned or to the wish to control costs and avoid, as far as possible, any waste of financial, technical and human resources. It involves overnight hospital accommodation of the patient in question for at least one night.'

Thus, this category has two elements: a requirement related to planning needs, and a particular situation, i.e. hospital care with a one-night stay. The arguments of the Court for making hospital care subject to prior authorisation are now formulated as criteria: they have to be necessary for planning in order to ensure access, or to control costs and avoid waste. Member States have to make it clear that the authorisation is necessary for this purpose.

In the proposal, the planning requirement was defined more strictly: the consequent outflow of patients seriously undermines, or is likely to seriously undermine, the financial balance of the social security system and the planning and rationalisation of hospital capacity, the maintenance of a balanced medical and hospital service open to all, or the maintenance of treatment capacity or medical competence on the territory of the Member State concerned.

This text was previously used in the Kohll and Decker judgment (see Section 3.1 above) as a criterion for an objective justification that can limit the freedom of 
services. The need for planning was used as an alternative argument in the GeraertsSmits and Peerbooms judgment to justify authorisation for hospital treatment. Undermining of the financial balance is not necessarily a requirement following from the case law. However, in the latter judgment the Court considered that free movement can be limited only in the case of 'overriding reasons in the general interest capable of justifying a barrier to the principle of freedom to provide services'. Thus, the arguments of the Member State put forward as an objective justification have to be strong, according to the case law. This is not, as such, required by the present text of Article 8, which merely mentions the possibility of 'any waste' of resources.

Secondly, two perspectives of planning which justify an authorisation requirement - ensuring access to high quality treatment and the desire to prevent wastage - were mentioned in the judgments. The Directive now mentions these perspectives as alternatives, by using the word 'or'. This may create a danger that invoking the desire to control costs and avoid any wastage is already sufficient. Such an argument can be invoked very easily, but is not always consistent with the case law. From the case law it follows that, in respect of wastage, planning has to be necessary, since this would, inevitably, otherwise lead to wastage, and this is so important that it constitutes an overriding reason for limiting free movement. Because this requirement is not laid down, as such, in the Directive, it may considerably broaden the number of situations in which authorisation systems can exist. The requirements of the Directive may, thus, be less strict than those of the case law. As a result, the formula of the Directive can lead to legal uncertainty and incoherence between case law and the Directive.

The second element of the category relating to where an authorisation system is allowed is that hospital care is involved. Prior authorisation for hospital care was indeed allowed by the Court. The criterion that this care must involve staying at least one night in a hospital is new. This is an improvement, because it makes more of a distinction than before between hospital and non-hospital care. As we saw in the Müller-Fauré and Van Riet judgment ${ }^{38}$ (Section 3.2), the Court found the distinction a difficult issue. This has now been clarified.

The new criterion seems to broaden the situations in which no authorisation is necessary ${ }^{39}$ since, if one makes use of a hospital without having to stay the night, there is no possibility of an authorisation requirement. However, there is also category (a-ii), which can include some situations in which a night is not spent in hospital, but where authorisation may still be required. This category concerns health care, in the context of planning requirements relating to access to high-quality treatment, or the wish to control costs and avoid waste, or the reduction of wastage, if it requires the use of highly specialised and cost-intensive medical infrastructure or medical equipment.

\footnotetext{
38 Case 385/99 [2003] ECR I-4503.

39 On the basis of the text in Müller-Fauré and Van Riet, discussed in Section 3.2, it can also be argued that, in some cases, the possibilities are narrowed.
} 
The exception of (a-ii) was new in comparison to the Müller-Fauré and Van Riet case law which existed before the proposal was made. However from the Commission $v$. France judgment ${ }^{40}$ it appears that the Court also accepts a system of prior authorisation for major medical equipment that is the subject of planning policy.

Category (b) includes treatments presenting a particular risk to the patient or to the population. There are no further requirements on planning and wastage, which follow from the nature of the risk involved. The Directive does not make clear what is meant by this category. Should we think of inadequate health care (risk to the person) or of a treatment that attracts a contagious disease (risk for population)? Given the possible justification mentioned in the Kohll and Decker judgment, this limitation to free movement appears acceptable.

These situations were also mentioned in the Commission proposal, but according to the text, the care mentioned in (a-ii) and (b) was to be included on a specific list made up by the Commission. It would thus be an EU list. Under the Directive, it is left to the individual Member States to decide, although the situations under (a) have to be notified to the Commission.

Category (c) is completely new and concerns health care that is provided by a health care provider that, on a case-by-case basis, could give rise to serious and specific concerns relating to the quality or safety of the care, with the exception of Union legislation ensuring a minimum level of safety and quality throughout the Union. It concerns persons with a bad reputation in cases where the Member State where the persons are working have not, themselves, set restrictions to their activities. ${ }^{41}$

Given the possible justifications mentioned in Kohll and Decker, this limitation to free movement appears acceptable: if the quality of the care is in danger, there is an objective justification to restrict free movement.

\subsubsection{When can authorisation not be refused?}

Member States must not refuse to grant prior authorisation when the health care cannot be provided on its territory within a time limit which is medically justifiable, based on an objective medical assessment of the patient's medical condition, the history and probable course of the patient's illness, the degree of the patient's pain, and/or the nature of the patient's disability at the time when the request for authorisation was made or renewed (Article 8(5)).

Article 8(6) mentions situations in which prior authorisation may be refused, without prejudice to Article 8(5): if there are particular patient safety risks, if there is a danger for the general public, and if there are serious concerns relating to the standards

$40 \quad$ Case C-512/08, European Commission v. French Republic, not yet reported in ECR.

41 This text, in particular the exception, is somewhat strange. If care could give rise to serious concerns relating to the quality and safety, authorisation can be refused unless it is subject to Union legislation ensuring a minimum level of safety and quality. Is the idea here that, in that case, the Commission has to undertake steps to have the quality improved so that it is of sufficient quality? 
on quality of care and patient safety. The last situation in which authorisation can be refused is that the health care can be provided on its territory within a time limit which is medically justifiable, taking into account the current state of health and the probable course of the illness of each patient concerned.

This text makes the rules relating to waiting lists quite confusing: Article 8(5) specifies when undue delay prohibits non-granting authorisation, and Article 8(6) specifies when the absence of undue delay allows the refusal the authorisation although the wording of both provisions is not the same.

The text of Article 8(5) follows from the Müller-Fauré and Van Riet judgment, and the text of Article 8(6)(d) is the text of the Coordination Regulation (Article 20(2)). According to the Court (in Watts), the criteria should be interpreted in the same way, so the difference in wording should not constitute a legal problem. Still, it is a remarkably inefficient way of drafting a text, and it could lead to problems when not accurately transposed into national legislation.

Moreover, although Article 8(5) follows the text of Müller-Fauré and Van Riet, it merely mentions the word disability, whereas the Court used the phrase 'disability which might, for example, make it impossible or extremely difficult for him to carry out a professional activity'. The relationship with the effects of carrying out work enshrined in the phrase does not automatically follow from the term disability in a strictly medical sense. The Court's formula is, therefore, an important addition, and is unfortunately not used in the Directive.

In Article 9(3), it is provided that Member States shall set out reasonable periods of time within which requests for cross-border health care must be dealt with and make them public in advance. When considering a request for health care, they shall take into account: (a) the specific medical condition, and (b) the urgency and individual circumstances. In the proposal, the patient's degree of pain, the nature of the patient's disability, and the patient's ability to carry out a professional activity, were also mentioned. So, in this provision, the relationship with work is also left out.

\subsubsection{Rules relevant to situations in which no authorisation is allowed}

\subsubsection{Additional limitations to free movement}

Article 7(8) provides that the Member State of affiliation shall not make the reimbursement of costs of cross-border health care subject to prior authorisation, except in the cases set out in Article 8.

However, in Article 7(9) the room for Member States to restrict cross-border movement is increased. They can limit the application of the reimbursement rules based on overriding reasons of general interest, such as planning requirements relating to the aim of ensuring sufficient and permanent access to a balanced range of high-quality treatment in the Member State concerned, or to the wish to control costs and to avoid, as far as possible, any waste of financial, technical and human 
resources. ${ }^{42}$ This limitation is restricted to what is necessary and proportionate, and may not constitute a means of arbitrary discrimination or an unjustified obstacle to the free movement of goods, persons or services. Member States have to notify the Commission of such decisions.

This provision thus allows Member States to apply a system in which reimbursement is limited rather than an authorisation system. Note that the term 'limit' is not further regulated; it can mean that no reimbursement is given at all, or that a lower amount than applicable under the regular rules is reimbursed.

One way of applying this rule is that, instead of having an authorisation system for hospital care abroad, a Member State can apply a reduction to the reimbursement normally applicable. This may have advantages for the patient, since no particular procedure needs to be followed, and authorisation should not be refused. However, this provision can also be used to limit reimbursement in situations other than those mentioned in Article 8, e.g. by setting a certain ceiling for expenditure, or by excluding it. Since the wish to control costs is one of the arguments for doing so, this provision may be used to limit free movement, and can depart considerably from the criteria mentioned in the case law. The criterion of 'wishing to control costs' is certainly not the same as that in the case of non-hospital care developed by the Court in Kohll and Decker: 'the risk of seriously undermining the financial balance of the social security system may constitute an overriding reason in the general interest capable of justifying a barrier of the kind at stake'.

It is, therefore, improbable that all use that can be made of this provision will stand the test of the Court. The Commission will have an important task in supervising the use of this article.

\subsubsection{Rules to better implement the case law}

There are also rules which are helpful for elaborating the case law and making sure that Member States follow it. Some provisions are also helpful, as they require information arrangements to be implemented by the Member States.

\subsubsection{Reimbursement rules}

The Directive requires Member States to put in place a transparent mechanism for cost calculation for cross-border health care, which is based on objective, nondiscriminatory criteria known in advance (Article 7(6)). This provision is also found in the Watts judgment, and is an important rule for realising cross-border health care, since some Member States do not have a set of defined reimbursement levels for particular types of care. This is, for example, the case in health systems with integrated It is remarkable that in this formula the term 'overriding reasons of general interest' is used, whereas
this was left out in Article 8, where it also would have been appropriate, see previous section. 
public financing and provision. In these cases the need for reimbursement constitutes a problem; the Directive requires Member States to solve this.

\subsubsection{Information}

The Commission's Working Paper and the Memorandum to the Draft Directive pointed out that it is often difficult for patients and professionals to identify what rights exist for reimbursement for cross-border health care. This was confirmed by a Eurobarometer survey, ${ }^{43}$ which showed that 30 per cent of the citizens in the European Union are not aware of the possibility of receiving health care outside their country. The Member States' answers to a Commission questionnaire also noted this uncertainty. ${ }^{44}$ Uncertainty and confusion regarding reimbursement rules are likely to make it more difficult for patients to avail themselves of their rights in practice.

In addition, it was reported that there have been problems with the exchange of information between the care providers in the host state and the state of affiliation and with the availability at home of drugs and medical devices prescribed abroad. ${ }^{45}$

The authors of the draft Directive wished, therefore, to establish a clear framework for cross-border health care by providing sufficient clarity on rights of reimbursement for health care provided in other Member States in order for those rights to be realised in practice, and ensuring that the necessary requirements for high-quality, safe and efficient health care would also be ensured for cross-border care.

This is laid down in the Directive. Member States have to ensure that there are mechanisms in place to provide patients, on request, with information regarding their rights and entitlements in that Member State relating to receiving cross-border health care, in particular as regards the terms and conditions for reimbursement of costs in accordance with Article 7(6), the procedures for accessing and determining those entitlements, and for appeal and redress if patients consider that their rights have not been respected, in accordance with Article 9. Thus, they do not have the duty to actively give information on getting cross-border health care.

In addition, national contact points for cross-border health care have to be established (Article 6(3)) in order to enable patients to make use of their rights in relation to cross-border health care; Member States have to provide patients with information concerning health care providers, including, on request, information about a specific provider's right to offer services, or any restrictions to its practice, as well as information on patients' rights, complaints procedures and mechanisms for seeking remedies, according to the legislation of that Member State, as well as the legal and administrative options available to settle disputes, including in the event of harm arising from cross-border health care.

\footnotetext{
43 Gallup (2007).

44 European Commission (2008: 12).

45 European Commission (2008: 14).
} 


\section{ASSESSMENT OF THE DIRECTIVE}

In the introductory section of this contribution, the question of whether and how the Directive will reinforce the legal position of patients who wish to obtain medical care abroad was asked. A second question concerned the coherence of the patients' rights law. The two questions are, of course, related, but there are also differences and, for this reason, they are discussed separately.

\subsection{IMPROVEMENT OF THE POSITION OF PATIENTS}

The Directive lays down several rules following from, or related to, the case law of the Court of Justice, including the rules on reimbursement and the requirements for administrative procedures, the conditions for a prior authorisation system, and the rules in situations other than where an authorisation system is allowed.

In addition, areas are regulated which have not been touched by the case law of the Court, since the requests for a preliminary ruling did not ask questions on these areas. An important aspect is the position of the state of treatment, to which Article 4 of the Directive is dedicated. It provides that the principle of non-discrimination with regard to nationality shall be applied to patients from other Member States. This is an important extension. Thus, patients cannot be asked to pay higher fee or be treated differently because of their nationality. However, an exception to this nondiscrimination rule applies if it can be justified by planning requirements related to access, or to the avoidance of waste and the control of costs. However, such measures are limited to what is necessary and proportionate, may not constitute a means of arbitrary discrimination, and have to be made publicly available in advance.

Article 11 lays down the rules on the recognition of prescriptions issued in another Member State, and apart from the exceptions listed in the Directive, any restrictions on the recognition of individual prescriptions are prohibited.

These additions may contribute to better free movement of patients, and may add to the rights already established by the case law.

\subsection{THE COHERENCE OF PATIENTS' RIGHTS IN CROSS-BORDER HEALTH LAW}

The case law of the Court on the Treaty created a new way of obtaining planned care abroad, in addition to the Coordination Regulation. This has led to a dual system and the differences are described in Section 3.4. The question arises as to whether the Directive has reduced the inconsistencies, has left them intact, or may even contribute to them. 


\subsubsection{The relationship between the Directive and the Coordination Regulation}

As Article 2 reads, the Directive shall apply, without prejudice, to the Regulation. Thus, the system of the Regulation has remained in place next to that of the Directive. This is important, since the Regulation is, if authorisation is granted, more beneficial to patients than the Directive.

In the Commission proposal, Member States were given the duty to always apply the more beneficial rules. Article 3(2) of the proposal provided that when the circumstances under which an authorisation to go to another Member State in order to receive appropriate treatment under the Coordination Regulation must be granted are met, the provisions of that Regulation shall apply and the provisions of reimbursement of the Directive shall not apply. When the conditions for granting an authorisation set out in the Coordination regulation are met, the authorisation shall be accorded, and the benefits provided in accordance with that Regulation.

During the discussions in the Council, this provision on the automatic application of the most beneficial rules did not survive. The Directive (Article 2) still provides that it is without prejudice to the Coordination regulations; Article 8(3) provides that with regard to requests for prior authorisation made by an insured person with a view to receiving cross-border health care, the Member State of affiliation shall ascertain whether the conditions laid down in Regulation 883/2004 have been met. Where those conditions are met, prior authorisation shall be granted, pursuant to that Regulation, unless the patient requires otherwise. There seems to be a difference between the original wording and the actual text, in that the actual text explicitly refers to 'requests for prior authorisation'. So, if a person makes such a request, the Regulation has to be applied. However, in the situation where a person could have made such a request, but has not done so, and has obtained health care abroad, there may be a difference between the draft text and the final text. Following the draft text, the Regulation had to be applied in such a case. In the final text this is not required. Recital 31 of the Directive reads that where the patient is entitled to cross-border health care under both the Directive and the Regulation, and the Regulation is more advantageous to the patient, the patient's attention should be drawn to this by the Member State of affiliation. It may be helpful if the patient contacts the benefit administration before going abroad to obtain health care. However, the provision is not very strongly worded, and it is unclear what its effects are if the Member State does not comply with the recital.

From the case law, in particular, the Vanbraekel ${ }^{46}$ and Elchinov judgments, ${ }^{47}$ it appears that sometimes persons cannot wait to obtain prior authorisation (procedures can be long, and bodies of first instance can make mistakes). In these cases, the Court decided that Article 20 of the Regulation is applicable. A strict interpretation of Article

\footnotetext{
Case C-368/98, Vanbraekel [2001] ECR I-5363.

47 Case C-173/09, Elchinov, not yet reported in the ECR.
} 
8(3) of the Directive would be contrary to the case law of the Court. In any case, it does not contribute to legal certainty by not laying down the automatic priority of the most beneficial rules.

Since the recital uses the phrase 'explicitly requests treatment under the terms of the Directive', we can conclude that if the patient does not follow the correct procedure and the Regulation's conditions are satisfied, s/he must still be awarded the most beneficial reimbursement. However, this is not laid down in the articles of the Directive itself, and that means that it does not have to be transposed, as such, into national legislation. As a result, it is much less certain whether automatic priority will be given. This may lead to serious uncertainty.

Moreover, there may also be uncertainty on what is meant by a patient 'explicitly requesting treatment'. Can such an explicit request follow from the behaviour of the patient, i.e. if $s /$ he goes directly to a care provider abroad? What if the patient is not willing to wait, since the authorisation procedure takes too much time? Is this also considered as 'explicitly requesting'?

In recital 46, it states that if authorisation is refused, and later on it is awarded, the Directive does not apply. This is consistent with the case law (Vanbraekel) ${ }^{48}$ (see, also, Section 3.2 above). Since this rule is not laid down in the main text of the Directive, it is not clear whether it will be transposed into national legislation. There are doubts as to whether this case law is currently being followed in all Member States.

The Directive does not oblige the state of treatment to inform the patient of his/her rights to reimbursement on the basis of the Regulation, so we cannot expect support from this side either. Since the Council decided to remove the priority provision from the proposal, we cannot be certain that all of them will be active in informing the patients of their rights. It is, therefore, unfortunate that the text was amended. ${ }^{49}$

\subsubsection{Are the rules coherently laid down in the appropriate instrument?}

Some of the patients' rights in cross-border health care are laid down in the Regulation, and some are laid down in the Directive. Moreover, the conditions in which authorisation must not be refused are laid down both in the Regulation and in the Directive, but there is a difference in the wording of these conditions. There is also a difference between the wording of the conditions of the Directive and in the case law, as seen in Section 4 above.

One could wonder whether it is desirable that some of the rules for elaborating the Regulation are laid down in a Directive. As a result, these rules will be laid down in national legislation, and in this way, there will be further interaction between the

\footnotetext{
$48 \quad$ ECJ Case C-368/98, Vanbraekel [2001] ECR I-5363.

49 During the discussions the recital of the proposal was also deleted, which read that the patient could choose which mechanism he preferred, but in any case, where the application of Regulation 1408/71 or $883 / 2004$ was more beneficial to the patient, the patient should not be deprived of the rights guaranteed by those Regulations.
} 
Regulation and national legislation. Differences in the way these rules are laid down can determine the effectiveness of the Regulation and can lead to legal uncertainty. Even though the Regulation has priority, inconsistencies can cause problems that are difficult to overcome, for instance, if persons make use of the Directive first, and then wish to invoke the Regulation. This is all the more problematic if patients are inclined to follow the procedures implemented on the basis of the Directive when they feel that the procedures for authorisation last too long, or because national legislation is simply more accessible to them.

Of course, some of the rules in the Directive may make the functioning of the Coordination Regulation smoother. Why, then, not spell out these rules, e.g. the authorisation rules, in the Regulation itself?

\subsubsection{Coherence in principles of reimbursement?}

There is, as we have seen, a fundamental difference between reimbursement on the basis of the Regulation, and on the basis of the Treaty. Under the Regulation, the full costs incurred by the institution of the state where the patient is treated are paid by the competent state; on the basis of the Treaty patients are reimbursed up to the amount that would have been paid had they obtained that treatment at home and patients bear the financial risk of any additional costs arising.

The Directive closely follows the approach of the Court of Justice to Article 56 TFEU. It thus leaves the different systems of reimbursement intact. The European Commission considered, in its memorandum to the proposal, that patients might prefer health care abroad for two main reasons:

- the health care that they need is just not available in their own system, at least not within a reasonable time; or

- that health care is available at home, but it is more convenient for them to have it abroad, because it is closer, quicker, or better.

The Commission argued that these are quite different reasons; one is a matter of need, the other is a matter of personal preference. Therefore, the Commission continued, it seems reasonable that they should be treated differently. If a patient has to go abroad to get the health care s/he needs because s/he cannot have it domestically, s/he should not lose out financially by doing so. But if s/he could stay at home and $s /$ he just prefers to have the health care abroad, there is no reason why public funds should have to pay any additional costs as a result. Therefore, the dual system based on this distinction remains. This line of argument was maintained during the discussions on the text of the draft Directive in the Council.

This means that the incoherence between principles of reimbursement has not been removed. The adoption of the Directive could have been an opportunity for doing so. After all, the Court's case law was based on the argument that higher costs were 
not an objective justification for hindering free movement, since Member States did not have to pay more for treatment abroad than under the domestic rules. Moreover, the judgments were considered already radical enough; an author called the Kohll and Decker judgments 'a conceptual transformation in the territorial identity of the welfare State. ${ }^{50}$ The Court would have overstepped the mark if it had not limited expenditure following on from its interpretation of the Treaty.

The EU legislature, however, had the freedom to introduce a different approach. It is therefore interesting to look at the arguments of the Commission. These arguments are based on the difference between the circumstances of patients and are not very strong. It is true that in the case of Kohll and Decker, it seemed a matter of their own preference to go 'shopping' abroad. In the other cases, we saw that waiting lists were long, or that particular treatments were not provided in the country of affiliation. So, it was not merely that it was 'more convenient' for the patients to go abroad.

Moreover, there is also a difference between systems that is not addressed by the Commission, i.e. under the Regulation the patient does not have to advance the costs, whereas under the Directive this is the case. Why not introduce a system in which the costs are paid by the Member State of affiliation directly to the host state? Under the present rules it is primarily the wealthier and better-informed European citizens who benefit from the rules, because treatment abroad requires pre-payment. This means that a person must have the financial means to be able to advance payments.

In view of these rules, citizens living in countries with expensive systems are more likely to go for treatment to countries with low cost systems; movement in the other direction is practically excluded. The fairness of this effect can be seriously put into question.

\subsubsection{Conclusion}

Recital 30 of the Directive mentions that the two systems of reimbursement should be coherent. During the negotiations on the text, an explicit objective was added to Article 1, i.e. that this Directive should also aim to clarify its relationship with the existing framework on the coordination of social security rights - Regulation $883 / 2004$ - with a view to its application to patients' rights.

However, this coherence requirement means - according to this recital - that either the Directive or the Coordination Regulation applies. Thus, according to the Directive, coherence does not mean a clear order of priority of the instruments or the automatic priority of the most beneficial one. Nor does it mean that the approaches of the instruments are the same. Therefore, in the same medical situation differences in procedure follow, and (lack of) knowledge may lead to incoherent outcomes: one patient may receive greater reimbursement than the other, while their situations are comparable. We can therefore conclude that, in order to create legal certainty and

$\overline{50 \quad \text { Dougan (2009). }}$ 
clarity for patients, this relationship could have been regulated much more explicitly than was done in the text of the Directive.

\section{DISCUSSION AND CONCLUSIONS}

\subsection{CROSS-BORDER MOVEMENT: A THREAT TO NATIONAL SYSTEMS?}

In the literature there has been a great deal of discussion on whether or not the case law of the Court on cross-border patient rights is a threat to national systems. ${ }^{51}$

As we have seen in the previous sections, the Court is, from its case law, very well aware of the risks which might exist in the case of uncontrolled and unlimited cross-border movement. For instance, getting care abroad is possible only if the care in question is also provided within the state of affiliation itself, so no expenses for new types of care are created; and the rates of reimbursement are no higher than they would have been had the care been provided in the state of affiliation. If the Member State can show that, as a result of cross-border movement, their planning will be jeopardised, or the financial equilibrium will be threatened, limits to cross-border care without prior authorisation are allowed. In this respect, it is relevant that crossborder expenditure on health care has, so far, been very limited, and that there are no problems in that regard. If there were such problems, and these were demonstrated by the Member States, particular restrictions could be allowed. To date, Member States have provided very little evidence in cases before the Court that there have really been any threats to their systems.

However, there remains one additional source for extra expenditure, i.e. that authorisation for hospital care has to be given, under some conditions, in the case of waiting lists. This is the case only if the specific criteria, to be considered in the individual case, are fulfilled. Sokol (2011) makes a matter of principle of this rule, since he sees the case law as a restriction of Member States' discretion to allocate resources to those most in medical need. However, he also acknowledges that it is often very difficult for an individual to invoke, within the national context, a right to a specific treatment (ibid: 322 ). In the case law of the Court, we can, indeed, see very complicated procedures and arbitrary and contrary decisions that take a very long time (e.g. in the Vanbraekel, Watts, Elchinov judgments) when authorisation is requested. As Sokol (ibid.: 340) writes: '[T]he approach in Watts entailed the unlawfulness of a national social security provision (such as prior authorisation) under the need to justify it, under the strict scrutiny of the Court.' Note that the first part of the sentence is not correct: the provision is only unlawful if it is unjustified. The need for justification is therefore crucial. As was already noted, within national law, it is difficult for individuals to get

$51 \quad$ For instance, Cabral (1999); Cabral (2004); Hatzopoulos (2002); Newdick (2005); Newdick (2006), Newdick (2009) and Newdick (2011). 
a justification, and we have also seen, in the Court judgments, the justifications given by the Member States are often weak. Therefore, the need to give a justification, which follows from the case law, is an important gain, and also relevant to national citizens.

Moreover, as a result of the case law, Member States can also take action to reduce their problems in ways other than having to authorise individual cross-border movement. For instance, the Netherlands has made arrangements with hospitals in neighbouring countries to treat patients.

\subsection{THE DIRECTIVE: MORE OR LESS COHERENCE?}

The picture arising from the discussion on the Directive is a mixed one. There have been improvements in respect of the rights of the patients, but there are also inconsistencies resulting from the new instrument. So, the answers to the questions in the first section are: yes, the legal position of patients is improved, since there are more facilitating rules, e.g. on transparent reimbursement systems. However, the dual system has remained intact, and the law has not been simplified. One could even say that it has become a three-tier-system of Regulation, Directive and case law. As a result, the better informed, and also more affluent, citizens have better chances of benefiting from the rules. Several inconsistencies mentioned may lead to uncertainty for potential migrant patients, and this may impede their going abroad.

This double answer reflects the tension between promoting free movement that fits with the concept of European citizens, and the more national approach followed to protect the national systems. The deviation from case law criteria and the lack of clarity vis-à-vis the priority in practice of the Regulation and the Directive were introduced in order to reduce, or in any case, to restrict, the use of the patient rights.

Since invoking the Treaty can restrict improper use of these provisions of the Directive, this situation again has the result that the better informed can more easily make use of the cross-border patient rights than others. It also has as a result that in new case law some of the national decisions based on the Directive may be overruled. Maybe this is the way the EU and EU law have to develop. Whether it will contribute to the popularity of Europe is another issue.

\section{REFERENCES}

Baeten, R. and Palm, W. (2011) 'The Compatibility of Health Care Capacity Planning Policies with EU Internal Market Rules', in VAn De Gronden, J.W. et al. (eds.) Health Care and EU Law, The Hague, TMC Asser Press.

Baquero Cruz, J. (2011) 'The Case Law of the European Court of Justice on the Mobility of Patients: An Assessment', in Van De Gronden, J.W. et al. (eds.) Health Care and EU Law, The Hague, T.M.C. Asser Press. 
Cabral, P. (1999) 'Cross-Border Medical Care in the European Union: Bringing Down a First Wall', European Law Review, 24(4), 387-395.

Cabral, P. (2004) 'The Internal Market and the Right to Cross Border Medical Care', European Law Review, 29(5), 673-686.

Davies, G. (2011)'Legislating for Patients' Rights', in Van De Gronden, J.W. et al. (eds.) Health Care and EU Law, The Hague, T.M.C. Asser Press.

Dougan, M. (2009) 'Expanding the Frontiers of Union Citizenship by Dismantling the Boundaries of National Welfare States?', in BARnard, C. and Odudu, O. (eds.) The Outer Limits of European Union Law, Oxford, Hart Publishing.

European Commission (2008) Commission Staff Working Document, accompanying the proposal for the patient mobility directive, SEC(2008) 2163, Brussels, European Commission.

Gallup (2007) Cross-border Health Services in the EU, Flash Eurobarometer Series \#210, Brussels, European Commission.

Hatzopoulos, V. (2002) 'Killing National Health and Insurance Systems but Healing Patients? The European Market for Health Services after the Judgments of the ECJ in Vanbraekel and Peerbooms', Common Market Law Review, 39(4), 683-729.

Jorens, Y (2003) 'Cross-Border Health Care in the European Union: Up to a Free Movement of Patients?' in Gesellschaft für Versicherungswissenschaft und Gestaltung (Social Security for Frontier Workers in Europe), Berlin.

Marhold, F. (2009) 'Modernisation of European Coordination of Sickness Benefits', European Journal of Social Security, 11(1-2), 119-132.

Newdick, C. (2005) Who Should We Treat?, Oxford, Oxford University Press.

Newdick, C. (2006) 'Citizenship, Free Movement and Health Care: Cementing Individual Rights by Corroding Social Solidarity', Common Market Law Review, 43(6), 1645-1668.

Newdick, C. (2009) 'The European Court of Justice, Trans-National Health Care, and Social Citizenship: Accidental Death of a Concept?', Wisconsin International Law Journal, 26(3), 844-867.

Newdick, C. (2011) 'Disrupting the Community - Saving Public Health Ethics from the EU Internal Market', in VAN De Gronden, J.W. (eds.) Health Care and EU Law, The Hague, T.M.C. Asser Press.

Pennings, F. (2010) European Social Security Law, Antwerp, Intersentia.

SAUter, W. (2009) 'The proposed patients' rights directive and the reform of (crossborder) health care in the EU', Legal Issues of European Integration, 36(2), 109-131.

Sokol, T. (2011) 'Entitlement to Socially-covered Health Care vs. Priority Setting: ECJ's Decomposition of the NHS?', European Journal of Social Security, 13(3), $317-350$.

Szyszczak, E. (2011) 'Patients' Rights: a Lost Cause or Missed Opportunity?', in Van De Gronden, J.W. et al. (eds.) Health Care and EU Law, The Hague, T.M.C. Asser Press. VAn de Gronden, J.W. et al. (eds.) (2011) Health Care and EU Law, The Hague, T.M.C. Asser Press. 